\title{
XXV. On the permeability of various bodies to the chemical rays
}

\section{Robert Hunt}

To cite this article: Robert Hunt (1840) XXV. On the permeability of various bodies to the chemical rays, Philosophical Magazine Series 3, 16:101, 138-142, DOI:

10.1080/14786444008649997

To link to this article: http://dx.doi.org/10.1080/14786444008649997

曲 Published online: 01 Jun 2009.

Submit your article to this journal $₫$

Џll Article views: 1

Q View related articles $₫$ 
of Boetius was not introduced by him. It does not appear to me that much authority ought to be given to the wellknown passage of William of Malmsbury, ${ }^{*}$ as far as it is supposed to prove that Gerbert brought the knowledge of the abacus from Spain: and, as Professor Peacock† so well observes, "the passage of this historian contains no certain intimation of the knowledge of the notation by nine figures and zero, as the rules which would be thence derived, would tend rather to relieve than increase the labours of the sweating calculators,"-que a sudantibus abacistis vix intelliguntur. Now had the question of the Boetian contractions been broached when Professor Peacock composed his history of arithmetic, he would immediately have seen how evidently this passage refers to them, and this supposition would have explained his doubts in the remaining part of his argument.

In the treatise of Berhelinus in the Bodleian libraryf, the Boetian contractions occur explained by Greck numerals, a most singular and important fact, and one which affords a very strong argument for what $M$. Chasles has stated at p. 474 of his Aperçu Historique. En passant, this is also an argument for the antiquity of this artificial abacal system.

Again, what difference is there between the system of the Greeks, the system in the Mentz Manuscript, the system in the passage in Boetius as satisfactorily explained by $\mathbf{M}$. Chasles, and the Arabic method? I mean with regard to first principless. All, in fact, are contained in the following formula, which is the general expression for any finite number: :-

$$
\mathrm{N}=a_{m} 10^{m}+a_{m-1} 10^{m-1}+a_{m-2} 10^{m-2}+\ldots+a_{1} 10+a_{0},
$$

where $a_{0}, a_{1}, a_{2}, \ldots a_{m}$ are digits, or integers less than the radix 10 .

XXV. On the Permeability of various bodies to the Chemical Rays. By Ronert Hun't.\|

HAVING many years since repeated, with much interest, the experiments of Wedgwood, Davy, and Wollaston on the chemical influence of light, it was with much pleasure

- Wright's Essay on Anglo-Saxon Literature (p.66).

+ History of Arithmetic, p. 415.

I I possess a transcript of this manuscript, but, having mislaid it, am compelled to defer any commentary on it till M. Chasles has published his edition.

\$ M. Chasles, Aperçu Historique, p. 474.

II Communicated by the Author. 
that I read Mr. Talbot's paper on photographic drawing, which opened to me new views, and pointed out paths rich in the promise of important results.

The vast sum of delight which the pursuit of this subject during the past year has afforded me, makes me a large debtor to that erudite gentleman, which I thus humbly, but sincerely, acknowledge.

My first endeavours in the photographic art were directed to restoring the natural order of light and shadow; and I fortunately succeeded in effecting this very early in the summer of 1839. My next were to improve the camera for photographic purposes, in which object I was most materially assisted by Mr. John Towson, of this town, who, having directed much of his attention to optics, furnished me with information and instruments by which my progress was greatly accelerated*.

Having, in conjunction with this gentleman, while trying a variety of lenses, been often perplexed by the dissimilar results obtained on the same paper from different kinds of glass, I was induced to commence a series of experiments on the interference of transparent bodies to the permeation of chemical light.

The same subject has, I am informed, engaged the attention of two scientific inquirers on the continent; but beyond a brief notice of M. Edmond Becquerel's experiments in the Athenæum, No. 621, I am perfectly unacquainted with the methods or results of their observations.

Being anxious to obtain a measure of the interference of the various bodies I was about to examine, I constructed a very delicate galvanometer - the coil being of ribbon copper and the needles of French watch-spring. To this instrument I connected, by platina wires, a $U$ tube, as suggested by M. Becquerel in his Traité d'Electricité, which held in one arm a solution of nitrate of silver, and in the other a solution of iodide of potassium. Every part of the tube was screened from light, except the lowest point, at which the fluids met. On this point, by means of a powerful lens, a concentrated pencil of light was thrown, which was made to pass through the bodies to be examined. The force of electro-chemical action being dependent on the quantity of chemical light impinging on the exposed portion of the fluids, led me naturally to conclude that the deflections of the needle would furnish very accurate comparative results. I have also tried the plan M. E. Becquerel adopts, of floating one photometric fluid upon

* See L. and E. Phil. Mag. for November last, vol. xv. p. 381.-Edit. 
another. Experience has, however, convinced me that the galvanometer, although capable of being made in the hands of a skilful manipulator a very accurate measurer of the diurnal variations of the quantity of chemical rays in the solar beam*, cannot be depended on where a series of nice comparisons are required. I have never yet been enabled to arrive at precisely the same results by this instrument in any two sets of observations; every thin cloud or the lightest smoke materially altering the deflections. I have, however, found it of use in giving me near approximations to a correct arrangement. I proceed thus : having by the galvanometer tabulated a number of bodies, I select those whose interference seems to approach near each other, and place them in regular order, under the same circumstances, upon a sheet of highly sensitive photographic paper in a dark room; then opening the window-shutters, expose it for three minutes to the direct influence of the solar rays, or for twice that time to diffused daylight; again darkening the apartment I examine the tints at which the paper has arrived under each body, and mark their correspondence or otherwise with the observations by the galvanometer. By carefully repeating many times each set of experiments, I am enabled to correct small errors of observation.

I use yet another method to test the correctness of the foregoing processes, which consists in filling a camera with the fluid or gas to be examined, or interposing the solid body and receiving the sun's image on a disc of silvered copper, prepared according to the principles of the Daguerreotype.

As many simple contrivances will suggest themselves to those who are desirous of repeating the experiments, it may be sufficient for me to state, that my apparatus is simply one cylinder sliding within another for the purpose of adjusting the focus to the different densities of the bodies, and that the photographic disc is protected from the fluid or gas by a piece of tested plate glass well greased around the edges, as are also the cylinders, throughout their length.

This plan may appear open to some of the objections I have urged against the galvanometer; but, as from the sensitiveness of the preparation an exposure of thirty seconds is sufficient, you are enabled to select your moments of observation, and

* Long prior to the publication of the speech of M. Arago on the report of the Commission on the Daguerreotype, both Mr. Towson and myself had remarked that the light of morning acted more powerfully on photographic preparations than the evening light. The paper which at nine in the morning became in ten minutes a rich purple bronze, took alm ost twice that time to reach the same hue at three in the afternoon. 
using the galvanometer at the same time to mark the intensity of light, try every substance under precisely the same circumstances. Having completed the exposure of a series, I place all the discs in the mercurial vapour-box together, and the instant the impression appears the strongest, remove them and carefully compare effects.

The following are the results $I$ have arrived at by these means. At the head of each series I have placed the mean permanent deflection of the galvanometer needle, from ten careful experiments with each of the bodies included within it. By this means a comparative view is given of one series with another.

Series 1.-Deflection $22^{\circ} 30^{\prime \prime}$.

Nitrogen

Atmospheric air

Oxygen

Hydrogen

Carbonic Acid

Carbonic Oxide

Steam (invisible)

Nitrous Oxide

Water

Alcohol (absolute)

Fther (sulphuric)

Series 2.-Deflection $20^{\circ}$.

British Plate Glass

Iceland Spar

Carbonate of Soda

Nitrate of Potassa

Ditto, fused and opake

Camphor

Sulphuric Acid

Hydrocyanic Acid(Scheele's)

Nitric Acid

Series 3.-Deflection $18^{\circ} 80^{\prime \prime}$.

Crown Glass

Flint Glass

Mica

French Plate Glass

Alum

Gurn Arabic

B. Plate and Crown Glass
German Plate (with a pink shade)

Two pieces of Crown Glass

Purple Fluor Spar

Nitrous Acid Gas

Iodine Vapour

Series 4.-Deflection $17^{\circ} 15^{\prime \prime}$.

B. Plate and Flint Glass

Flint and Crown Glass

Three pieces of Crown Glass

Three laminæ of Mica

Creosote

Oil of Aniseed (German) Peppermint (English)

-2. Rosemary

Savine

Four pieces of Crown Glass

Amber

Green Fluor Spar

Oil of Lavender Caraways

Cloves

Canada Balsam

Series 5.-Deflection 4. 35".

Green Bottle Glass*

Chlorine

Protoxide of Chlorine

Bromine (vapour)

Briquid)

Lightly-smoked Glass

* I have been much surprised at some of the mimufacturing chemists in London sending out their hydrocyanic acid and other easily decomposable preparations in bottles of purple glass, which offers no interruption to the chemical rays. Dark green glass should be substituted. 
It is necessary I should state that the results are likely to be differently recorded by different observers, unless the same photographic preparation is used in all cases. I have been in the habit of using a paper washed with a solution of the muriate of baryta and nitrate of silver, while it is yet damp. The sensitiveness of this preparation may be shown by the fact of its being acted on very decidedly in five minutes by a gas flame from a ten-holed Ârgand burner. On this paper the tints are blue under greenish glasses, while under those inclining to a yellow they are reddish. If a paper prepared with a solution of the chloruret of soda be used, the tints are reddish under the green, and bluish under the pure white or yellowish glasses.

The above list does not contain all the bodies $\mathbf{I}$ have examined, but they are all I am satisfied to place in a determinate position.

Not having deduced any fixed principles from my observations, I may appear to act prematurely; but as it is probable the same subject may be engaging those whose minds and means are superior to my own, and as it is possible even my humble experiments may be of service to such persons, I feel myself excused from the charge of obtrusiveness.

12, Cornwall Street, Devonport, January 2, 1840.

XXVI. On an anomalous Electric Condition of Iron. By Martyn J. Roberts, Esq.

To the Editors of the Philosophical Magazine and Journal. Gentlemen,

$\mathrm{T}$ is now some months since, that while prosecuting a series of novel galvanic experiments, I discovered a singular anomaly in the electric condition of iron, which is, that although iron if associated with copper as a galvanic pair is highly positive to the copper, yet when associated with zinc, it is more highly negative to the zinc than copper would be under similar circumstances; or in other words, that although copper and iron form a galvanic combination, in which the iron is in the same relation to the copper that a zinc plate would be, yet that iron and zinc form a galvanic pair that has a greater power of generating electric action than a similar sized pair of copper and zinc. This singular phænomenon will, I believe, lead the way to some important discoveries; but not to occupy too much space in your valuable Journal, I will without further comment give extracts from my notebook of some experiments made by me on this subject. 